\title{
O desempenho econômico brasileiro em 2011 e perspectivas para 2012: uma análise rápida em um período complexo ${ }^{\dagger}$
}

Cleomar Gomes da Silva* Fábio Henrique Bittes Terra**

Resumo: O ano de 2011 foi complexo: por um lado, em âmbito internacional, ele apresentou a continuidade da crise econômica iniciada com o subprime americano em fins de 2007, porém, com efeitos intensificados sobre a Europa e, em especial, sobre a Zona do Euro. Por outro lado, em âmbito doméstico, assistiu-se a preocupações: inicialmente, sobre o comportamento da inflação e, a partir de meados do ano, sobre o desaquecimento da economia (sinal tanto do cenário externo quanto das políticas domésticas para estabilização dos preços). É diante deste cenário complexo que este artigo analisa o desempenho da economia brasileira em 2011 bem como aponta perspectivas para tal desempenho em 2012. As conclusões denotam que tanto no âmbito interno, quanto no externo, o ano de 2012 apresenta-se como uma reprodução, mais animadora, no entanto, de 2011.

Palavras-chave: Desenvolvimento econômico; Economia brasileira; Políticas econômicas.

Classificação JEL: E00; E20; E60.

\footnotetext{
${ }^{\dagger}$ As opiniões expressas neste artigo são de responsabilidade dos autores e não refletem a posição do Ministério da Fazenda. Os autores agradecem a assistência de pesquisa prestada por Fernando Aguiar e Lucas Dantas.

* Doutor em Economia pela Fundação Getúlio Vargas (FGV). Assessor da Secretaria de Política Econômica do Ministério da Fazenda e professor adjunto do Instituto de Economia da Universidade Federal de Uberlândia (UFU). Endereço eletrônico: cleomargomes@ie.ufu.br.

** Doutor em Economia pela Universidade Federal do Rio Grande do Sul (UFRGS). Professor adjunto do Instituto de Economia da Universidade Federal de Uberlândia (UFU). Endereço eletrônico: fhbterra@ie.ufu.br.
} 


\section{Introdução}

Não restam dúvidas de que o ano de 2011 foi repleto de desafios para a economia brasileira que, ao longo do ano, enfrentou um cenário difuso tanto em âmbito doméstico quanto internacional. No cenário doméstico, 2011 foi marcado pela acomodação da atividade econômica, após crescimento considerável de 2010, pela retirada dos estímulos fiscais contracíclicos, além das tradicionais preocupações com o controle da inflação e com o comportamento da taxa de câmbio. No cenário internacional, houve intensificação da crise econômica na Zona do Euro, ainda uma continuação do 'débâcle' global de 2008/2009. Isso sem contar os problemas de negociação do nível de endividamento dos Estados Unidos.

É nesta conjuntura complexa que este artigo pretende analisar a performance da economia brasileira em 2011, com os objetivos de sumarizá-la e de trazer perspectivas para 2012. Para tanto, o texto contará com três seções, além desta introdução. Na primeira seção, far-se-á uma breve análise da economia brasileira em 2011 enquanto que, na segunda, serão apontadas as perspectivas para 2012. Por fim, apontam-se as considerações finais.

\section{O desempenho da economia brasileira em um cenário complexo}

O ano de 2011 começou despertando preocupações governamentais com a trajetória de crescimento econômico e, consequentemente, com a trajetória de inflação. Dado o efeito das políticas contracíclicas implementadas entre 2008 e 2009, o Brasil obteve uma considerável expansão de seu Produto Interno Bruto (PIB) em 2010 (7,5\%), melhor desempenho desde os idos de 1986. Este cenário, aliado a outras diversas fontes de pressão, fizeram com que a inflação brasileira se apresentasse preocupante em razão, principalmente, do comportamento dos preços internacionais das commodities, de quebras de safra observadas nos primeiros meses do ano, da pressão dos preços de serviços, além da habitual força da demanda doméstica. A Tabela 1 mostra o comportamento da inflação brasileira tanto do IPCA, com diversas desagregações, quanto do IGP-DI e projeção do IPCA para 2012. 
Tabela 1 - Taxas de inflação 2011 e projeções 2012 (\% a. a.)

\begin{tabular}{l|ll}
\hline \multirow{7}{*}{2011} & IPCA & 6,5 \\
& Alimentação e bebidas & 7,2 \\
& Habitação & 6,7 \\
& Artigos de residência & 0,0 \\
& Vestuário & 8,3 \\
& Transporte & 6,0 \\
& Saúde e cuidados pessoais & 6,3 \\
& Despesas pessoais & 8,6 \\
& Educação & 8,1 \\
& Comunicação & 1,5 \\
& IPCA Livres & 6,6 \\
& Serviços & 9,0 \\
& IPCA Monitorados & 6,2 \\
& IGP-DI & 5,0 \\
& IPA-DI & 4,1 \\
& IPC-Br & 6,4 \\
& INCC-DI & 7,5 \\
\hline \multirow{2}{*}{2012} & IPCA 2012 & 5,2 \\
& IGP-DI* 2012 & 4,6 \\
\hline
\end{tabular}

Fonte: IBGE, FGV, BC.

Nota: *Relatório Focus do BC, 2 de março de 2012.

A resposta imediata do Banco Central do Brasil foi um ciclo de elevações da taxa básica de juros, iniciada antes mesmo da sucessão presidencial em janeiro de 2011. Entretanto, houve algumas peculiaridades dignas de destaque. Primeiramente, a alta dos juros foi, em grande parte, de 25 pontos-base, o que significou uma elevação da taxa Selic de 11,25\% em janeiro de 2011 para 12,50\% em julho do mesmo ano (Gráfico 1). Em segundo lugar, diferentemente do hábito desde 1999, quando da implementação do regime de metas de inflação, as autoridades monetárias passaram a instrumentalizar as chamadas medidas macroprudenciais, limitando a aceleração da demanda sem a necessidade de ajustes mais intensos da taxa básica de juros. Ademais, com regras mais rígidas sobre as concessões de crédito, houve consequente acomodação dos spreads bancários, diminuindo o custo do dinheiro para os tomadores de recursos financeiros.

O Gráfico 1 mostra que a trajetória ascendente dos juros foi interrompida em agosto de 2011, em vista das seguintes causas principais: 1) o acirramento da crise europeia e suas repercussões diretas sobre a demanda por exportações no Brasil, bem como seus reflexos indiretos sobre o custo das commodities; 2) a contribuição das medidas macroprudenciais sobre o crédito e de controle de 
capitais.

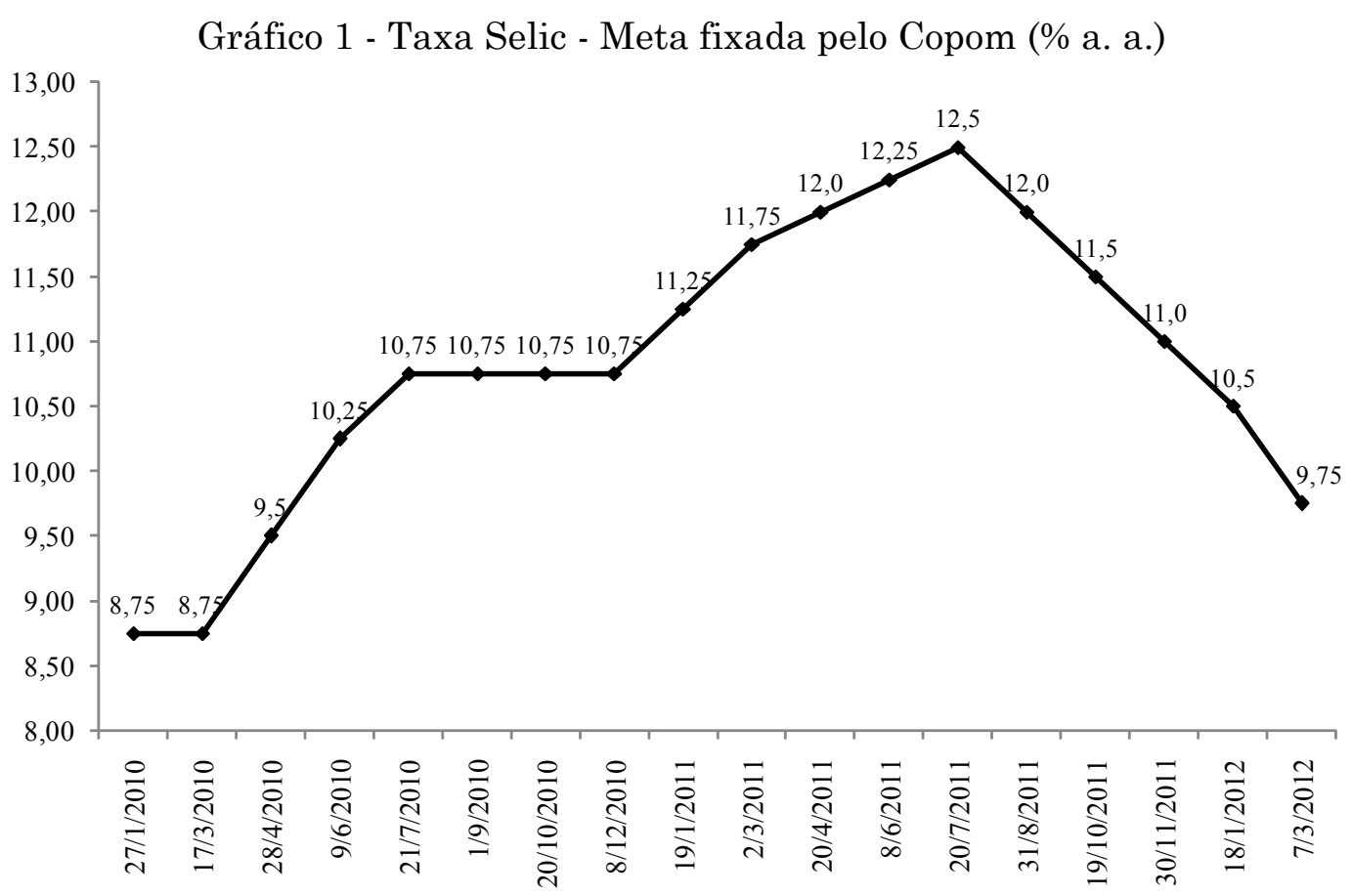

Fonte: Banco Central do Brasil.

Em outro flanco, o Governo iniciou um programa de consolidação fiscal em 2011, com o início da retirada dos incentivos fiscais concedidos durante a crise global de 2008/2009, além do comprometimento com o cumprimento da meta cheia de superávit primário de $\mathrm{R} \$ 117$ bilhões, meta esta elevada para $\mathrm{R} \$ 127$ bilhões, devido à inclusão de receitas extraordinárias. Neste particular, a política fiscal foi outro fator a contribuir com o esforço da política monetária em 2011. A economia primária do Governo central alcançou $\mathrm{R} \$ 93$ bilhões (2,3\% do PIB) e do setor público consolidado alcançou $\mathrm{R} \$ 128,7$ bilhões, o que equivaleu a $3,10 \%$ do PIB (Tabela 2).

Ainda que a economia de recursos primários tenha sido recorde em 2011 e que a taxa de juros básica tenha se mantido em patamares inferiores àqueles do período 1999/2008, as necessidades nominais de financiamento do setor público somaram $\mathrm{R} \$ 107,9$ bilhões, ou $2,61 \%$ do PIB. Isso significa que o pagamento com juros comprometeu 5,72\% do PIB, chamando a atenção para a importância das novas formas de se conduzir a política monetária: os juros são auxiliados pelas medidas macroprudenciais e as perspectivas futuras importam mais na determinação dos juros do que o peso do passado ${ }^{1}$.

1 Sobre o caráter foward looking da política monetária, ver Nakano (2011).

Revista Economia \& Tecnologia (RET)

Vol. 8(1), p. 7-18, Jan/Mar 2012 
Tabela 2 - Resultado fiscal: Governo central e setor público consolidado $(\mathrm{R} \$$ milhões e \% do PIB)

\begin{tabular}{l|r|r|r|r}
\hline \multicolumn{1}{c}{ Governo central } & $\mathbf{2 0 1 0}$ & $\mathbf{2 0 1 1}$ & $\mathbf{2 0 1 0}$ & $\mathbf{2 0 1 1}$ \\
\cline { 2 - 6 } & $\mathbf{R} \$$ milhões & R\$ milhões & \% PIB & \% PIB \\
\hline Receita bruta & 844.966 & 990.406 & 22.4 & 24.0 \\
Transferências para estados e municípios & 140.678 & 172.483 & 3,70 & 4,2 \\
Receita líquida & 704.287 & 817.923 & 18.7 & 19.8 \\
Despesas primárias & 657.394 & 724.403 & 17.4 & 17.5 \\
Resultado primário & 78.723 & 93.035 & 2.1 & 2.3 \\
Juros nominais & -124.509 & -180.553 & -3.3 & -4.4 \\
Resultado nominal & -45.785 & -87.518 & -1.2 & -2.1 \\
\hline \multicolumn{1}{c}{ Setor público consolidado } & R\$ milhões & R\$ milhões & \% PIB & \% PIB \\
\hline Resultado primário & 101.696 & 128.710 & 2,70 & 3,11 \\
Resultado nominal & -93.673 & -107.963 & $-2,48$ & $-2,61$ \\
\hline
\end{tabular}

Fonte: STN e BC.

Não se pode deixar de destacar, ainda, a relevância das medidas de gerenciamento do fluxo de capitais, que buscam resguardar o balanço de pagamentos de volatilidade excessiva causada pelo fluxo de capital especulativo que se encaminha ao Brasil. Os impactos de desvalorizações cambiais sobre os níveis de inflação são constantes apontamentos nas Atas do Comitê de Política Monetária como definidores de prudência na condução da política monetária via juros básicos. De certa forma, a volatilidade cambial decorrente de movimentações de arbitragem ficou menos intensa com as seguintes taxações: 1) 6\% sobre os investimentos em portfólio de renda fixa; 2) 6\% sobre depósitos de margem em operações derivativas; 3) 6\% sobre a entrada de recursos externos com prazo de até 3 anos; 4) 1\% sobre a posição vendida excessiva em reais.

O Gráfico 2 mostra a trajetória da taxa de câmbio nominal no Brasil a partir de 2010. Nota-se um processo de valorização cambial até meados de 2011 , quando do início dos cortes na taxa de juros, das medidas de gerenciamento do fluxo de capitais, assim como em função da intensificação da crise europeia. $\mathrm{O}$ abrandamento, ainda que parcial, desta crise no final de 2011 e início de 2012 tem provocado uma reversão da taxa de câmbio tanto no Brasil quanto em vários outros países.

Por fim, do ponto de vista externo, o Brasil continuou se beneficiando dos preços internacionais das commodities, o que gerou um valor exportado de US $\$ 256$ bilhões e um saldo da balança comercial de US $\$ 29,8$ bilhões em 2011 , mesmo com as dificuldades cambiais enfrentadas. O fluxo de investimento estrangeiro direto alcançou US $\$ 66,7$ bilhões, auxiliando na estabilização do déficit em conta corrente do país em $2,1 \%$ do PIB. 


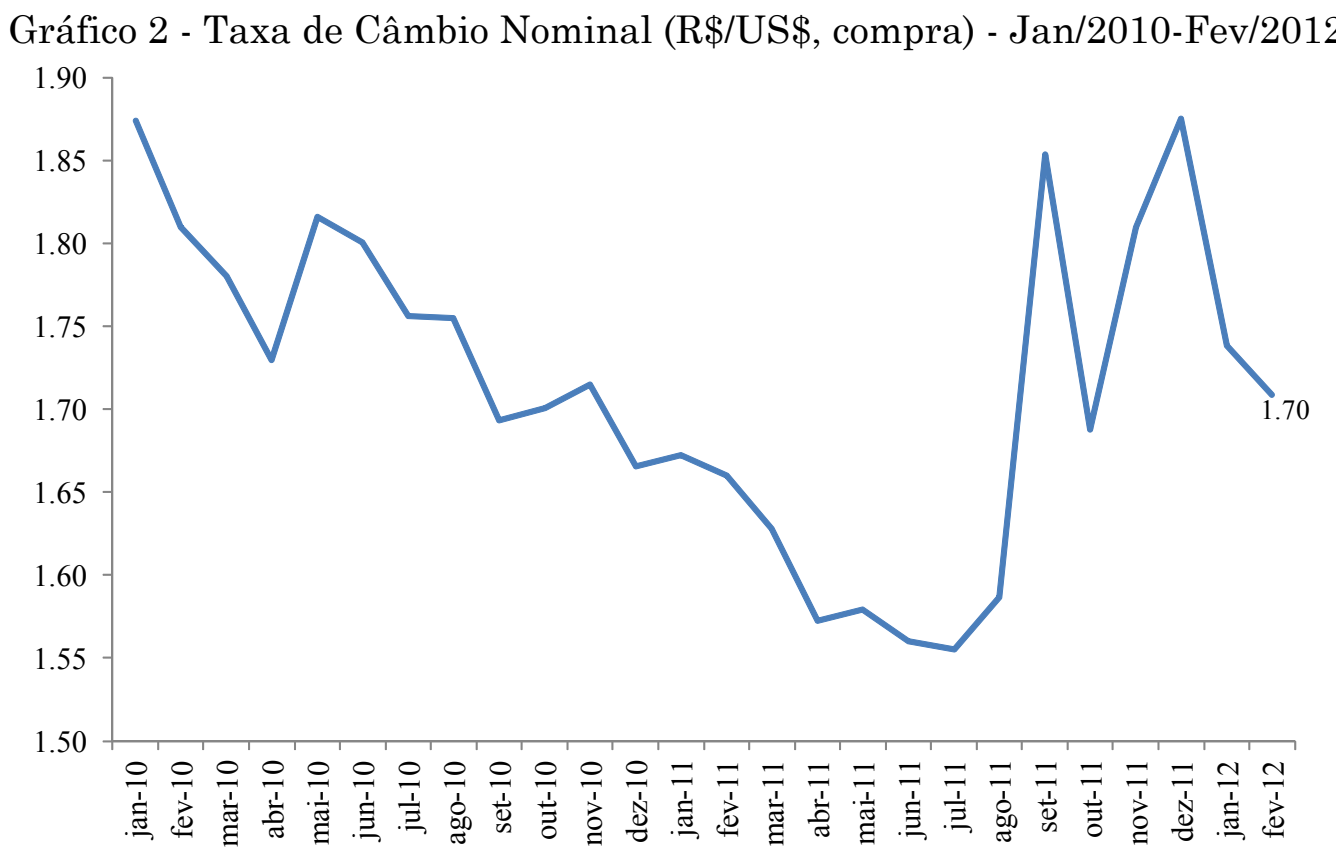

Fonte: Ipeadata.

Por sua vez, em termos de atividade econômica, fica evidente o cenário complexo aqui destacado. O início de 2011 reproduziu o início de 2010, com crescimento econômico expressivo, sendo este um dos fatores que justificavam a preocupação com relação à inflação. Contudo, ao longo do ano, a atividade econômica arrefeceu, em virtude dos efeitos das medidas governamentais adotadas, por um lado, e da intensificação da piora do cenário externo, por outro.

Diante destas novas circunstâncias que ameaçavam a continuidade de uma dinâmica estável da atividade econômica, o Governo passou a instituir medidas de estímulo à economia, dentre as quais, os cortes na taxa Selic, a redução de impostos a setores específicos e a reversão de algumas medidas prudenciais relacionadas ao crédito. Ademais, houve comprometimento com a continuidade dos investimentos decorrentes da segunda fase do Programa de Aceleração do Crescimento (PAC), canal pelo qual a demanda governamental pode estimular a estabilidade dos níveis de produção e investimento no país.

De todo modo, o Produto Interno Bruto brasileiro apresentou desempenho bem mais moderado do que em 2010, com crescimento anual de 2,7\% (Gráfico 3). O setor industrial foi o que mais sentiu o processo de acomodação da atividade econômica, somando-se a isso a competitividade ampliada em função da valorização cambial e as desconfianças do cenário turbulento na economia mundial. Logo, o ano de 2011 trouxe um crescimento praticamente nulo $(0,3 \%)$ Revista Economia \& Tecnologia (RET) 
da produção industrial medida pelo IBGE e expansão de 1,6\% do PIB industrial. A propósito, dada a competitividade internacional acirrada e problemas cambiais, a indústria de transformação fechou 2011 com déficit comercial de US $\$ 48,7$ bilhões e decrescimento da participação desse ramo do setor industrial no PIB de 16,2\% em 2010 para 14,6\% em 2011.

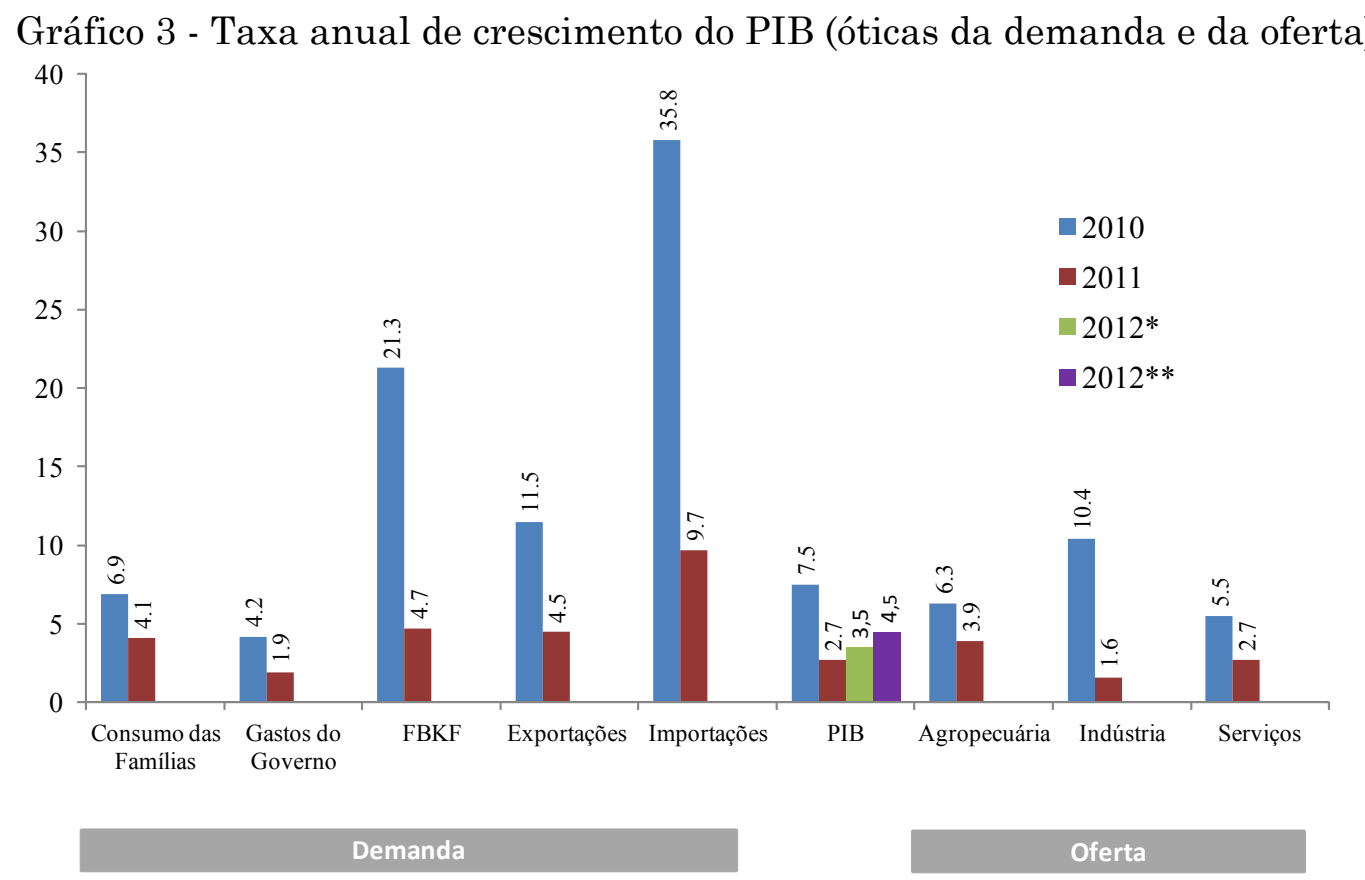

Fonte: IBGE.

Nota: "Projeção do Relatório de Inflação do Banco Central (Dezembro de 2011);

${ }^{* *}$ Projeção do Ministério da Fazenda.

Mesmo neste ambiente de crescimento mais acomodado do PIB, a taxa de desemprego calculada pelo IBGE alcançou o menor percentual de sua série histórica em dezembro de 2011: 4,7\% na série sem ajuste sazonal. Em média, a taxa de desemprego brasileira em 2011 foi de $6 \%$.

\section{Desafios e oportunidades no ano de 2012}

O ano de 2012 teve início com alguma perspectiva de melhora da crise econômica na Europa, inclusive com o Banco Central Europeu tendo deixado de hesitar a agir enquanto emprestador de última instância e injetando praticamente $€ 1$ trilhão no sistema financeiro europeu. Este cenário um pouco mais animador, e de maior liquidez, está causando a apreciação da maioria das moedas internacionais desde os últimos dias de 2011, incluindo o real, que acu- 
mulou valorização de cerca de $10 \%$ nos dois primeiros meses do ano. Tal dado apresenta que continua havendo entrada de recursos estrangeiros no Brasil, mesmo diante das medidas governamentais de gerenciamento de capitais e das quedas nas taxas de juros.

Mesmo diante da crise, o capital produtivo europeu aplicado no Brasil em investimento direto externo tem crescido. Entre 2010 e 2011, os ingressos para participação em capital nacional oriundos de um conjunto de 18 países (incluídos as Ilhas Cayman e Jersey), ampliaram-se em praticamente 100\%, segundo dados do Banco Central do Brasil. Comportamento similar pode ser verificado nos empréstimos intercompanhias oriundos da Europa. Talvez seja este um dado revelador não somente da atratividade da economia brasileira mas, principalmente, das causas da continuidade da crise na Europa. Os investimentos produtivos cada vez mais migram para os países emergentes, esfriando a dinâmica das economias europeias.

Corrobora este argumento as taxas de desemprego recordes. Dados da Eurostat, a agência de estatísticas da região europeia, mostram que a Espanha iniciou 2012 com desocupação superior a $20 \%$ da sua população economicamente ativa. A Zona do Euro como um todo está com taxa de desemprego de cerca de 10\%. Além disso, a previsão é de crescimento negativo na região em 2012.

Ainda que se destaque em atratividade, o desafio maior da economia brasileira em 2012 será o de sustentar seu crescimento com controle da inflação e com enfrentamento da questão cambial. As expectativas expressas pelos agentes financeiros, via Relatório Focus do Banco Central do Brasil, apontam para uma taxa de inflação fechando o ano de 2012 em 5,24\%, ao passo que as expectativas da autoridade monetária apontam para uma elevação do IPCA de 4,7\%. De todo modo, está havendo uma convergência da taxa de inflação em direção à meta, tudo dependendo do ritmo da atividade econômica ao longo do ano e do comportamento dos preços das commodities no mercado internacional.

Restam, entretanto, os reflexos do contágio do possível default grego, ainda que parcial, sobre os outros países delicadamente endividados da Zona do Euro, como Portugal, Espanha e Itália. Ainda assim, espera-se que uma vez solucionada a premente questão do endividamento grego, as instituições financeiras assumirão seus respectivos prejuízos em balanços e, daí em diante, buscarão composição de ativos em países mais estáveis, tal qual o Brasil. 
Um ponto a se destacar é a intenção já revelada do Banco Central do Brasil em continuar baixando a taxa de juros, tal como percebido nas reuniões já realizadas em 2012. Isso poderá contribuir para a melhora dos níveis de formação bruta de capital fixo do país, que crescem em percentual superior ao PIB desde 2005. Investimentos do Programa de Aceleração do Crescimento e dos eventos esportivos, dentre outros, proverão mais infraestrutura ao país. O BNDES também continuará atuando como ator de política contracíclica, via maiores desembolsos de crédito a pequenas, médias e grandes empresas bem como "market maker", que são fatores que viabilizam o impulso da economia.

Do lado fiscal, a intenção anunciada pelo Governo é alcançar a meta cheia de superávit primário da ordem de $\mathrm{R} \$ 139,8$ bilhões para o setor público consolidado. O Governo central ficará responsável por $\mathrm{R} \$ 97$ bilhões do montante total ao passo que as esferas subnacionais arcarão com $\mathrm{R} \$ 42,8$ bilhões. Este montante referente ao Governo central já está em linha com o contingenciamento anunciado em meados de fevereiro de 2012. A reprogramação orçamentária é uma nova leitura técnica dos números anteriormente estabelecidos na Lei Orçamentária Anual (LOA) de 2012 que, então, trazia uma estimativa de receitas (líquidas de transferências) da ordem de $\mathrm{R} \$ 937,8$ bilhões. De acordo com a nova proposta, este valor reduziu-se para $\mathrm{R} \$ 908,3$ bilhões. Já as despesas primárias foram reduzidas de $\mathrm{R} \$ 866,3$ bilhões para $\mathrm{R} \$ 811,3$ bilhões, gerando um corte nos gastos da ordem de $\mathrm{R} \$ 55$ bilhões. A diferença entre receitas e despesas é o que gerará a meta de superávit primário do Governo central de $\mathrm{R} \$ 97$ bilhões. Decerto, será um desafio considerável dadas as necessidades de intensificação dos investimentos públicos diante da crise e de continuação com os programas sociais em sua plenitude.

Neste ínterim, não custa lembrar que taxa de juros cadentes, aliadas a medidas macroprudenciais sobre o crédito e sobre fluxos internacionais de capital, gerarão menores gastos públicos financeiros com juros e amortizações do endividamento público. Se pelo lado primário os esforços já são feitos, a atual forma de condução das políticas monetária e cambial poderá conduzir a um melhor resultado nominal do setor público, pela redução das despesas financeiras.

Do ponto de vista externo, o saldo da balança comercial deverá ser bem mais modesto em 2012, por conta da queda da demanda internacional, da acomodação dos preços dos principais produtos exportados pelo Brasil (ambas as 
causas decorrentes da crise internacional) e da continuidade da competitividade internacional, principalmente na balança comercial da indústria. Pelo lado dos influxos de capitais estrangeiros as perspectivas são favoráveis. Ademais, com o estoque de reservas cambiais acumuladas pelo Banco Central (mais de US\$ 350 bilhões), as expectativas de restrição externa no curto prazo são bastante reduzidas, de tal sorte que restrições de influxos financeiros externos não deverão trazer preocupação ao longo do ano.

Em suma, as projeções do Banco Central apontam para um crescimento do PIB da ordem de 3,5\%, ao passo que o Ministério da Fazenda trabalha com percentual entre $4 \%$ e $4,5 \%$.

\section{Conclusão}

É relevante perceber que a indústria nacional, mesmo acometida pelos reflexos negativos da crise econômica, prevê recuperação em um futuro próximo, a ponto de, mesmo defronte o agravamento da crise internacional em 2011, manter suas inversões produtivas em patamar praticamente similar às de 2010 , quando o crescimento econômico alcançou 7,5\%. Os problemas principais a serem enfrentados centram-se no combate à inflação que não provoque diminuição na taxa de investimento do país e na resolução da questão da apreciação (ou da guerra) cambial intensificada pelo tsunami monetário, como definiu a Presidenta Dilma Rousseff, causado pela política monetária expansionista dos países desenvolvidos.

À parte as preocupações levantadas, as expectativas, no entanto, são favoráveis, ainda mais quando se considera a proximidade da Copa do Mundo de 2014 e das Olimpíadas de 2016, além do crescimento da renda per capita, da renda do trabalho e do contingente pertencente à classe média, fatores representativos do potencial do mercado interno nacional. No âmbito externo, sinais de recuperação da Zona do Euro, ainda que por conta de esforços políticos do que por resultados econômicos, trazem esperanças de que a crise tenha uma inflexão no curso prazo. Enfim, o ano de 2012 apresenta-se como uma reprodução mais animadora de 2011. O fundamental é que este momento de reordenação econômica mundial seja oportunamente aproveitado para se repensarem as políticas econômicas, alinhando os objetivos de crescimento econômico com estabilidade 
de preços e equilíbrio externo.

\section{Referências}

Banco Central do Brasil. (2011). Relatório de Inflação BCB, dezembro de 2011.

Banco Central do Brasil. (2012). Focus - Relatório de Mercado, 2 de março de 2012.

Castro, M. R.; Gouveia, S. N.; Minella, A.; Santos, R. C.; Souza-Sobrinho, N. F. (2011). "Samba: Stochastic Analytical Model with a Bayesian Approach". Banco Central do Brasil Working Papers, n. 239.

Ipeadata. (2012). "Dados de macroeconomia". URL [on-line]: http://www.ipeadata.gov. br. Acesso em: fevereiro de 2012.

Ministério da Fazenda. (2012). Economia brasileira em perspectiva, $14^{\mathrm{a}}$ edição.

Nakano, Y. (2011). "Olha para a frente”. Carta Capital XVII(678): 26-29. 
